\title{
Laser-Induced Copper Deposition with Weak Reducing Agents
}

\author{
V.A. Kochemirovsky", S.A.Fateev, L.S. Logunov, I.I. Tumkin, S.V. Safonov \\ Department of Chemistry, Saint-PetersburgUniversity, 198504 Saint-Petersburg, Petrodvorets, 26 \\ Universitetsky prosp., Russian Federation \\ *E-mail: lasergroupspb@gmail.com
}

Received: 5 October 2013 / Accepted: 17 November 2013 / Published: 8 December 2013

The study showed that alcohols with 1,2,3,5,6 hydroxyl groups can be used as reducing agents for laser-induced copper deposition from solutions (LCLD). Multiatomic alcohols, sorbitol, xylitol, and glycerol, are shown to be effective reducing agents for performing LCLD at glass-ceramic surfaces. High-conductivity copper tracks with good topology were synthesized. The work determines the regularity of changes in properties of metallic deposits depending on the reducing potential of the polyol.

Keywords: reducing agent, laser-induced deposition, copper, topology, xylitol

\section{INTRODUCTION}

Laser-induced deposition from solutions, LCLD, is a promising method of localized deposition of a metal on various substrates in the focus of the laser beam. The method allows you to create smallsized metallic structures (conductor width from units to 200 microns) without a photo mask on the surface of various dielectrics and semiconductors [1-4]. The greatest practical importance is the deposition of copper, which has a high electrical conductivity. Scanning with the focused laser beam the surface of a dielectric placed in a special copper plating solution initiates the localized chemical reaction of metallic copper reduction [4]. The reaction rate of copper deposition increases from $5 \mu \mathrm{m}$ per hour for the standard chemical copper plating up to $5 \mu \mathrm{m}$ per few seconds while the area is exposed to laser radiation.

Von Gutfeld [5-7] and Kordas et al [2] explain this effect by exclusively a thermal factor (increase the reaction rate of metal reduction with heat), as well as mixing the solution. In the experiments of von Gutfeld the laser beam was focused at the interface of copper electrode- copper sulfate solution. The second electrode is inserted in the solution, and external voltage was applied to the closed circuit resulting in the electrochemical reduction of copper on the surface of the copper 
plate. At low values of the external voltage $U$ one can watch the jump of potential $E$ the order of 0.4 at the copper-electrolyte solution surface during laser irradiation, which leads to a 1000 times increase in the copper deposition rate in the exposed area.

Using formaldehyde as a reducing agent in LCLD does not result in deposits with a quality topology [8-9] (hereinafter by the quality topology we mean the continuity of the copper structure by length and width and the lack of a diffuse plume of the non-localized deposited copper, i.e. copper reduced in the bulk solution and deposited around the track in the form of separate crystals) [10]. Copper structures appearing with the use of formaldehyde, have the electrical resistivity 2-4 orders of magnitude higher than that of pure copper[8] or have no conductivity [11].

However, it is found [12] that it is possible to significantly improve the quality of the topology and the conductivity of copper structures by using polyatomic alcohol, sorbitol, as a reductant. Results of copper deposition using formaldehyde and sorbitol are shown in Fig. 1 [4], [12].

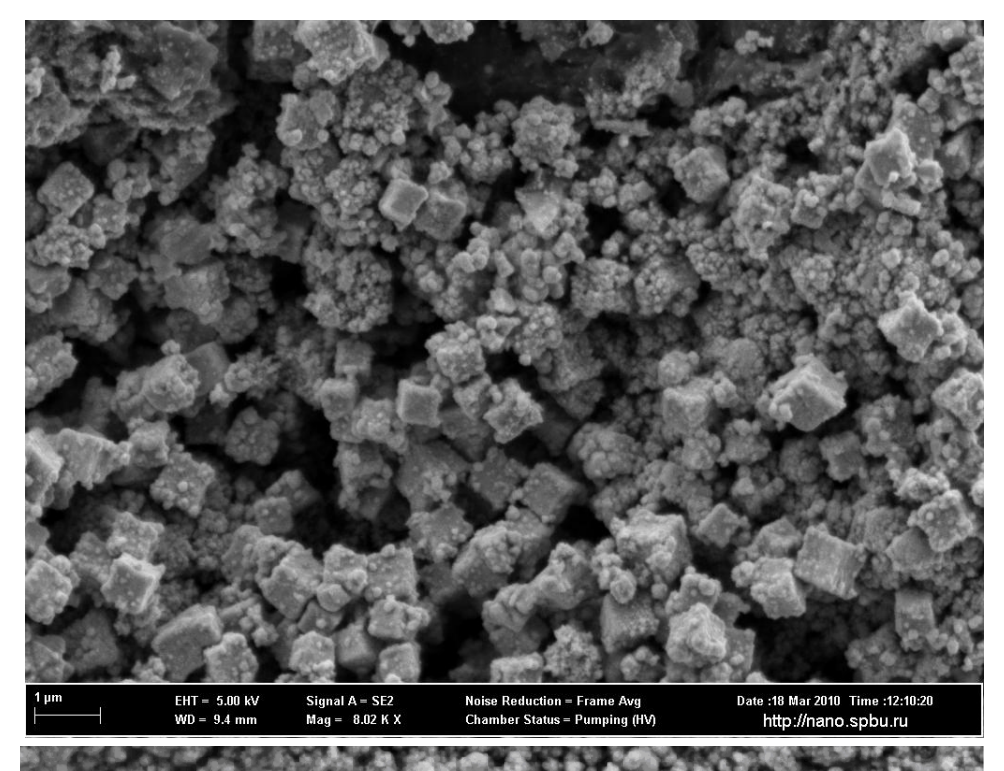

a)

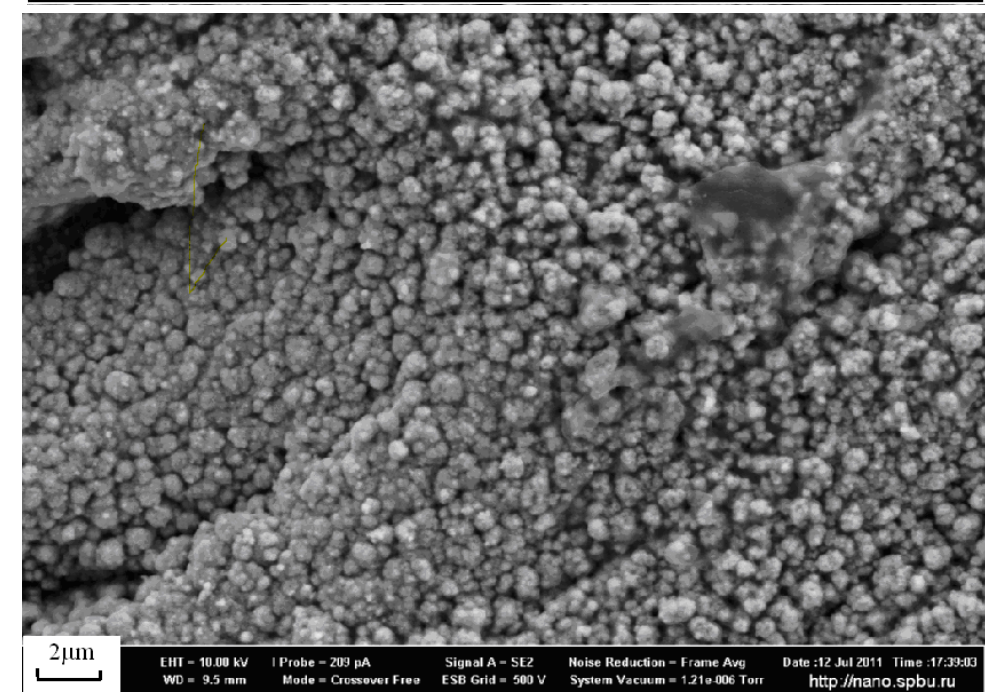

Figure 1. Micrographs of copper structures deposited by LCLD on the surface of a glass ceramics. Reproduced from [4] (a) and [12] (b) with the permission of the authors. 
Using sorbitol, we managed to produce a monolithic conducting deposit with an average size of particles 100 to $400 \mathrm{~nm}$. The value of specific electric resistance of the copper conductor $10 \mathrm{~mm}$ long is equal to $0.06 \mathrm{~mm}^{2} / \mathrm{m}$ being at least two orders of magnitude lower than for the deposits produced previously using formaldehyde but about 3-5 times higher than that of pure copper [12].

The result cannot be explained relying only on the thermal model of the increase of the deposition process rate under heating the solution and the substrate by the laser beam.

The present work reports the data that allow you to adjust the assumptions of von Gutfeld and Kordas of the thermal nature of the influence of laser radiation on chemical plating processes.

To this end we conducted an experiment on the use of reducing agents with low reduction capabilities: polyatomic alcohols (polyols) as reducing agents for LCLD copper deposition on the surface of the Sitall CT-50-1 glass ceramics that is used in microelectronics for manufacturing micro assemblies of microwave products. In this work we used a number of polyols with different reduction potentials, including those with negative difference of potentials with copper (II) in the solution. We also traced the influence of the polyol reduction potential on the process of laser deposition of copper.

\section{EXPERIMENTAL}

Fig. 1 shows the diagram of the experimental setup used to study metal deposition by LCLD.

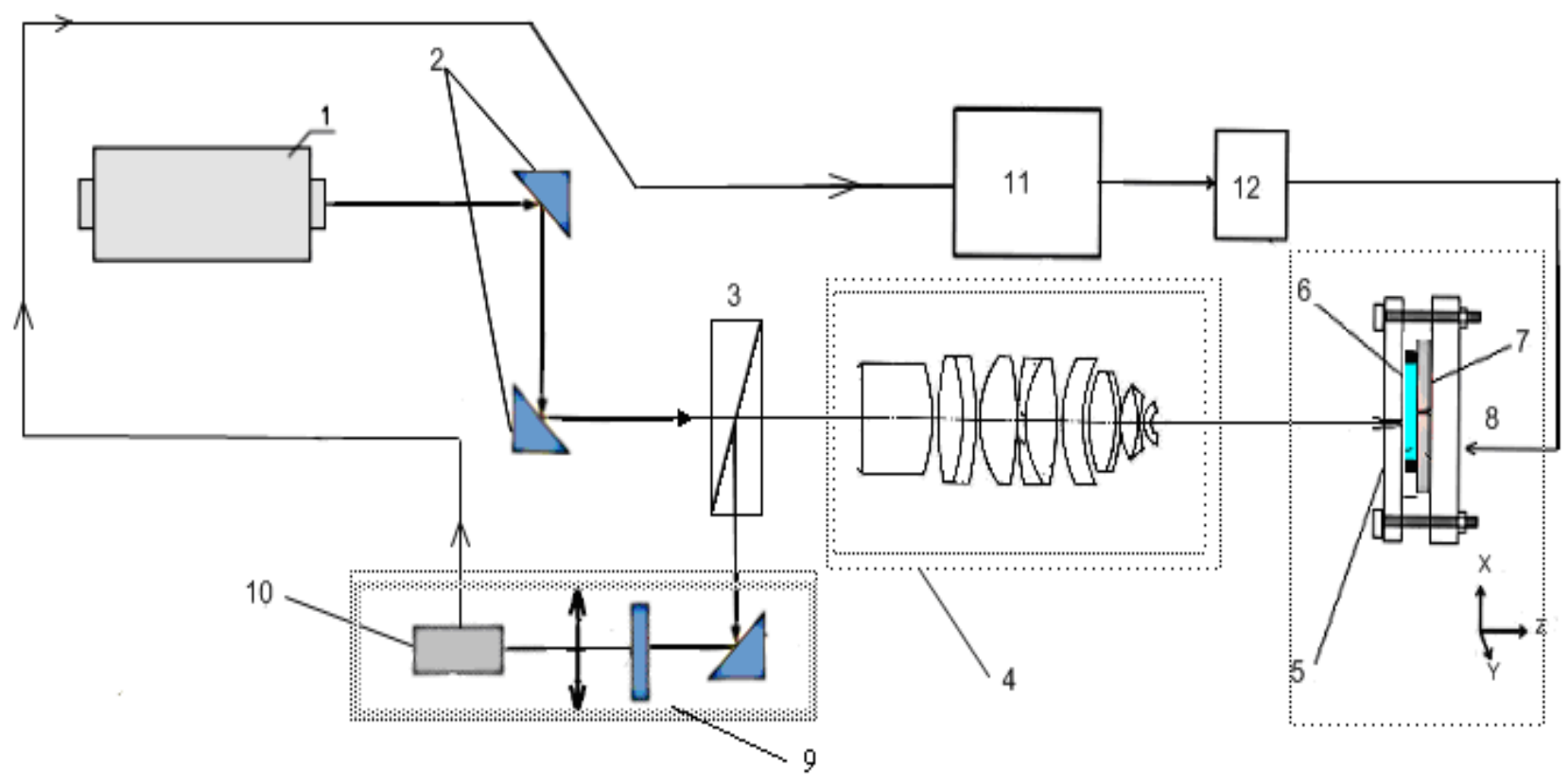

Figure 2. Schematic of the device for the laser-induced deposition of metals from solution.

A laser beam (1) was directed through a beam splitting cube (2) that diverted a portion of the laser radiation to the CCD camera for optical focusing and in situ monitoring of the metal deposition. The sample-targeted beam was focused to produce a $5-\mu \mathrm{m}$ spot at $1 / \mathrm{e} 2$ intensity using a $4 \mathrm{X}$ 
microscope objective lens (3) at the dielectric/solution interface. The dielectric was irradiated "from the side of the solution" for non-transparent substrates (glass-ceramics) and "from the side of the substrate" for transparent substrates. The dielectric and the electrolyte solution were placed on a motorised translation stage (7) driven by a controller (11). The operating commands from the computer (10) were generated using original software. The same computer received data from the CCD-camera (9) that was used to monitor the deposition process in real-time.

The copper structures were deposited using a continuous diode-pumped solid-state Nd:YAG laser (DPSS) operated at a power ranging from 100 to $2000 \mathrm{~mW}(\lambda=532 \mathrm{~nm})$. The laser beam was focused to a fixed spot $10 \mu \mathrm{m}$ in diameter on the dielectric surface.The substrate was translated on the motorised stage with respect to the focus point at a speed of $0.0025 \mathrm{~mm} / \mathrm{s}$ for the glass-ceramics substrate.

Copper was deposited onto dielectric substrate composed of the crystalline glass ceramic material Sitall, which is widely used in microelectronics. The composition of Sitall ST-50-1 is as follows: $\mathrm{SiO}_{2}(60.5 \%), \mathrm{Al}_{2} \mathrm{O}_{3}(13.5 \%), \mathrm{CaO}$ (8.5\%), $\mathrm{MgO}(7.5 \%), \mathrm{TiO}_{2}(10 \%)$.

SEM images were collected using a Zeiss Supra 40VP Field Emission Scanning Electron Microscope (FESEM) equipped with an Energy Dispersive X-ray (EDX) Spectrometer that was used for chemical analysis. The impedance spectra of the copper lines were recorded using an impedance meter Z-2000 by Elins Co. (Russia, Chernogolovka) employing the four point probe method at a frequency range of $20 \mathrm{~Hz}$ to $2 \mathrm{MHz}$ and a signal amplitude of $125 \mathrm{mV}$. Optical images were captured using an optical microscope with 20X magnification (MMN-2, LOMO).

The composition of the solution $\mathrm{C}$ for copper structures formation was $0.01 \mathrm{MCuCl} 2,0.05 \mathrm{M}$ $\mathrm{NaOH}, 0.03 \mathrm{M}$ potassium sodium tartrate (Rochelle salt), 0.075 M HCHO.

The composition of Solutions 1-4 for copper structures formation was $0.01 \mathrm{M} \mathrm{CuCl}_{2}, 0.05 \mathrm{M}$ $\mathrm{NaOH}, 0.03 \mathrm{M}$ potassium sodium tartrate (Rochelle salt) $\left(\mathrm{KNaC}_{4} \mathrm{H}_{4} \mathrm{O}_{6} \times 4 \mathrm{H}_{2} \mathrm{O}\right), 0.075 \mathrm{M}$ polyhydric alcohol. Solutions 1-4 included the following mono- and polyhidric alcohols: Solution 1 - ethanol, Solution 2 - ethylene glycol, Solution 3 - glycerol, Solution 4- xylitol.

All chemicals were of analytical grade purity.

\section{RESULTS}

In this work we have studied the processes of laser-induced deposition of copper from solutions containing polyatomic alcohols as reducing agents.

Copper structures differ significantly in topology and electric properties depending on the polyol and the deposition schedule. The following are examples of quality and poor topology of copper deposits. By the quality topology we mean the continuity of a copper deposit by length and width (Fig $3 b, c)$. Only copper structures with quality topology can conduct an electric current. By poor topology we mean gaps in copper structures (Fig.3 a). 


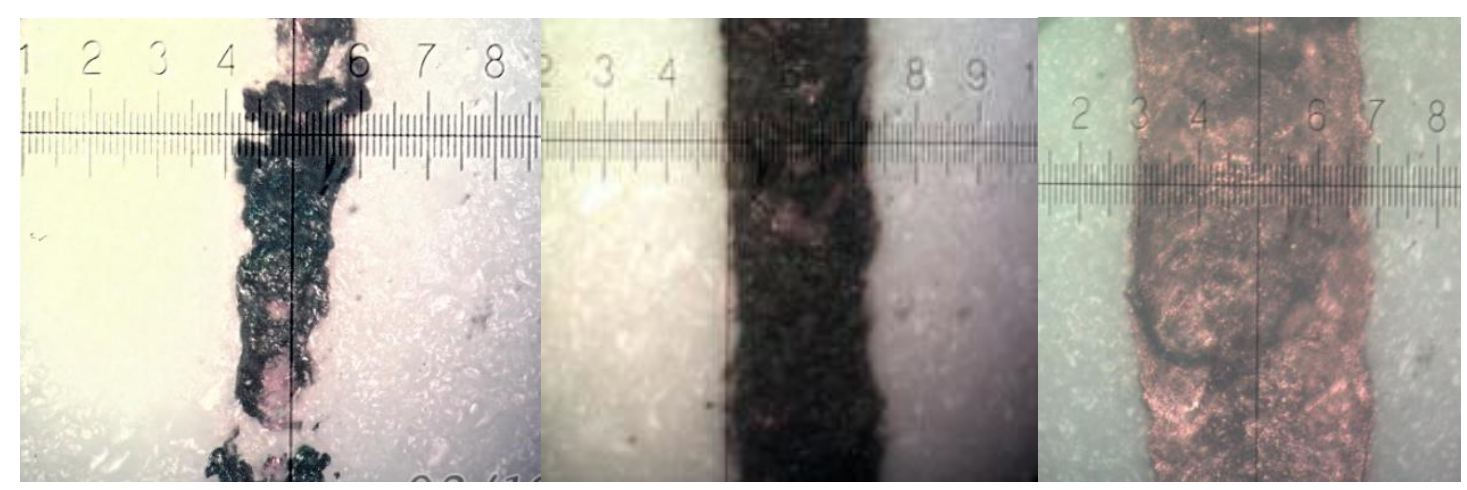

Figure 3. a) Copper structure with poor topology deposited from a solution with ethylene glycol at 300 $\mathrm{mW}$. b) Copper structure with quality topology deposited from a solution with an ethanol reductant at $1000 \mathrm{~mW}$; the structure has no copper luster. c) Copper structure with quality topology deposited from a solution with a xylitol at $1000 \mathrm{~mW}$; the structure has the copper luster.

\section{Formaldehyde}

We took formaldehyde as a reference reducing agent in this series of experiments because of its large reducing potential. The micrograph of the deposit obtained from the reference Solution $\mathrm{C}$ with formaldehyde reductant on the surface of the glass ceramics is shown in Fig. 5e.

The initiation reaction threshold (the minimum power needed to start the reaction) amounted to $300 \mathrm{~mW}$. The best copper topology structures were produced at capacity of $700 \mathrm{~mW}$, their width being 90-120 $\mu \mathrm{m}$ (Fig. 4a). The topology of the deposits is satisfactory, but the copper structure has a different width along the track $1 \mathrm{~cm}$. Average particles size of the deposit from Fig. 5e can be estimated as crystals 2-5 $\mu \mathrm{m}$ in size. The deposit is not compact; gaps between the crystals are visible. The resistance of the copper structure $1 \mathrm{~cm}$ long is not less than $1900 \mathrm{Ohm}$. The value of resistance is not stable in time and increases more than 3 times within a month (Fig 7). According to EDX (Fig 6a), the deposit consists of copper with minor additives of oxygen and carbon. Also, there is a signal aluminum on the spectrum, which we attribute to the substrate of the glass ceramics. Appearance of the aluminum signal may indicate either a thin layer of copper in this deposit or the discontinuity of the structure at the point of capture.

\section{Ethanol}

The threshold of reaction initiation was $300 \mathrm{~mW}$. Copper structures obtained from the solution with ethanol have poor-quality topology. Copper structures with fewest defects were produced at 900 $\mathrm{mW}$, their width being 120-130 $\mu \mathrm{m}$ (Fig 4a). Deposit average particles size at Fig. 5a can be estimated as crystals more than $1 \mu \mathrm{m}$ in size. The deposit is not densely packed and is formed as separate microcrystals. Copper structures produced with ethanol reductant do not conduct electrical current. According to EDX (Fig. 6b) the deposit consists of pure copper.

\section{Ethylene glycol}

The threshold of reaction initiation was $400 \mathrm{~mW}$. The best topology copper structures were produced at $700 \mathrm{~mW}$, their width being $130 \mu \mathrm{m}$ (Fig.4b). The copper structures do not possess copper 
luster, but have a quality topology (Fig.3b). Average particles size of the deposit from Fig. 5b can be estimated as $400 \mathrm{~nm}$. Crystals have the tetrahedral form. The deposit has a high density and is a continuous layer (Fig 4b). Microstructure of the deposit (Fig. 5b) reveals that the tetrahedral microcrystals are joined together by only faces and vertices, which can lead to an increase in electrical resistance. The resistance of the copper structure $1 \mathrm{~cm}$ long is not less than 80 Ohms. The resistance increases by $20 \%$ during the month. According to EDX (Fig6 b), the deposit consists of pure copper.

\section{Glycerol}

The threshold of reaction initiation was $400 \mathrm{~mW}$. The best topology copper structures were produced at $1000 \mathrm{~mW}$, their width being $170 \mu \mathrm{m}$ (Fig.4c). Produced copper structures have highquality topology (Fig. 3c). Deposit average particles size from Fig. 5c can be estimated as copper nanocrystals more than $100 \mathrm{~nm}$ in size. The deposit has a high density and is a continuous layer (Fig.4c). Microstructure of the deposit (Fig. 4 c) shows, in addition to a continuous layer of copper nanocrystals, the formation of individual crystals with a size of about $1 \mu \mathrm{m}$, which did not appear to be involved in conduction. The resistance of the copper structure $1 \mathrm{~cm}$ long is $2.7 \mathrm{Ohms}$. The specific resistance value is about 2.5 times higher than the value for pure copper. The resistance value is stable in time within 30 days (Fig. 7). According to EDX (Fig. 6 b) the deposit consists of pure copper.

\section{Sorbitol}

Experiments on the use of sorbitol as a reducing agent arepresented in [12] and in Fig.1.

The threshold of reaction initiation was $400 \mathrm{~mW}$. The best topology copper structures were produced at $1000 \mathrm{~mW}$, their width being more than $150 \mu \mathrm{m}$ (Fig.4c). Produced copper structures have high-quality topology but not copper luster (analogous to Fig. 3b). Deposit average particles size is 100-400 nm [12]. The deposit is a continuous layer [12]. The resistance of the copper structure $1 \mathrm{~cm}$ long is $5 \mathrm{Ohms}$. The resistivity of the produced conductor, according to the estimates made for the track profile with atomic force microscopy, amounted to about $0.06 \mathrm{Ohm} \mathrm{mm} / \mathrm{m}$, being 3 times higher the value of resistivity for pure copper. The resistance value is stable in time within 30 days (Fig. 7). According to EDX (Fig 6 b) the deposit consists of pure copper.

\section{Xylitol}

The threshold of reaction initiation was $400 \mathrm{~mW}$. The best topology copper structures were produced at $1000 \mathrm{~mW}$, their width being from 150 to $220 \mu \mathrm{m}$ (Fig.4d). Produced copper structures have high-quality topology and copper luster (Fig. 3c). Microstructure of the deposit (Fig.5d) has no expressed dispersion; the deposit looks continuos. The size of the crystals that form the deposit can be estimated as $10 \mathrm{~nm}$ or lower. The deposit is highly dense and presents itself a continuous layer (Fig.4c). The resistance of the copper structure $1 \mathrm{~cm}$ long is $1.5 \mathrm{Ohms}$. The resistivity of the produced conductor is close to the value of resistivity for pure copper. The resistance value is stable in time within 30 days (Fig. 7). according to EDX (Fig 6 b) the deposit consists of pure copper. 

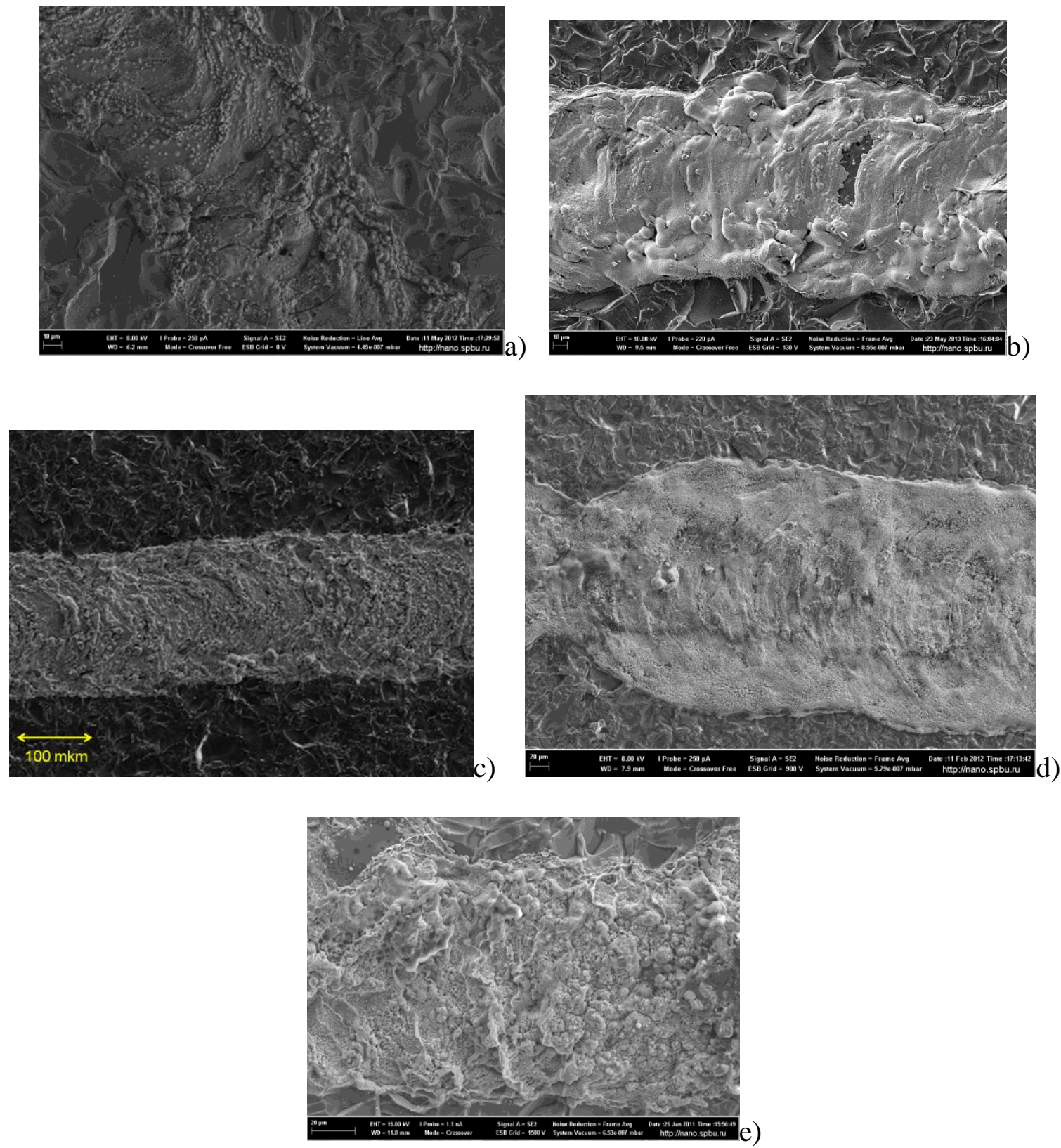

Figure 4. SEM and EDX data for copper structures produced when deposited with different reductants: a) ethanol; b) ethylene glycol; c) glycerol; d) xylitol; e) formaldehyde.
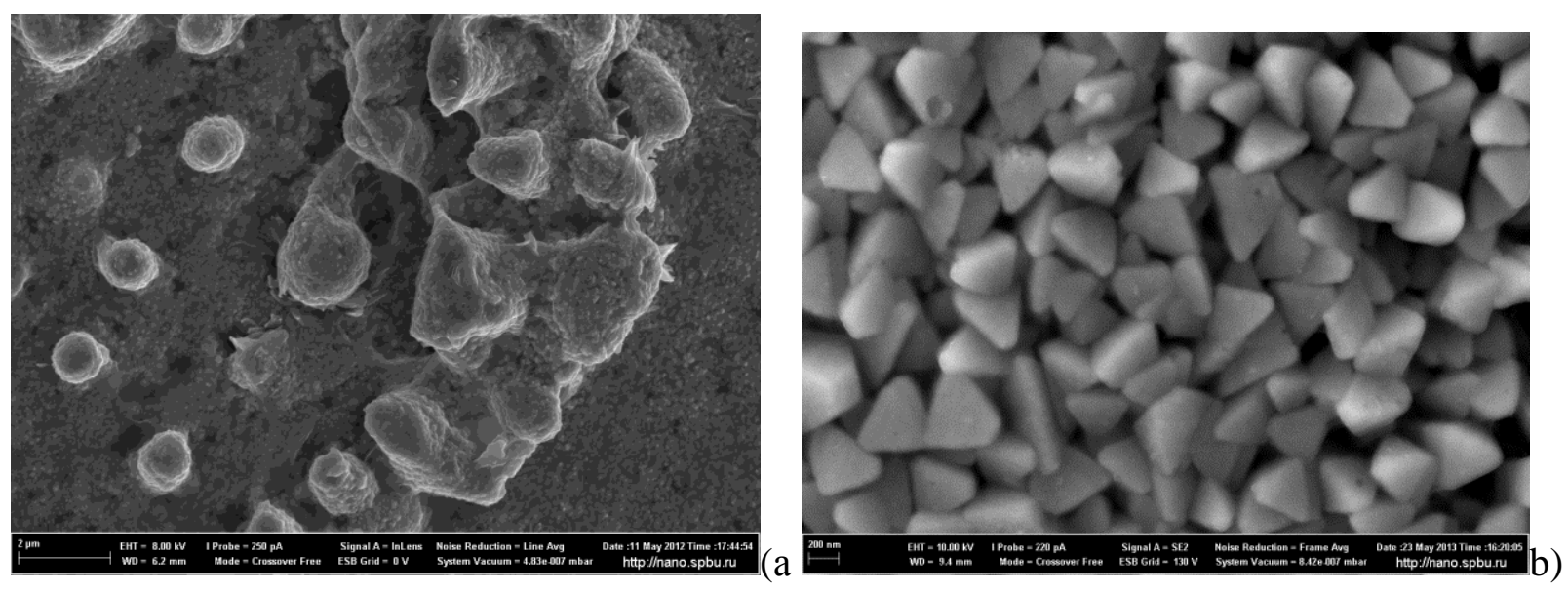

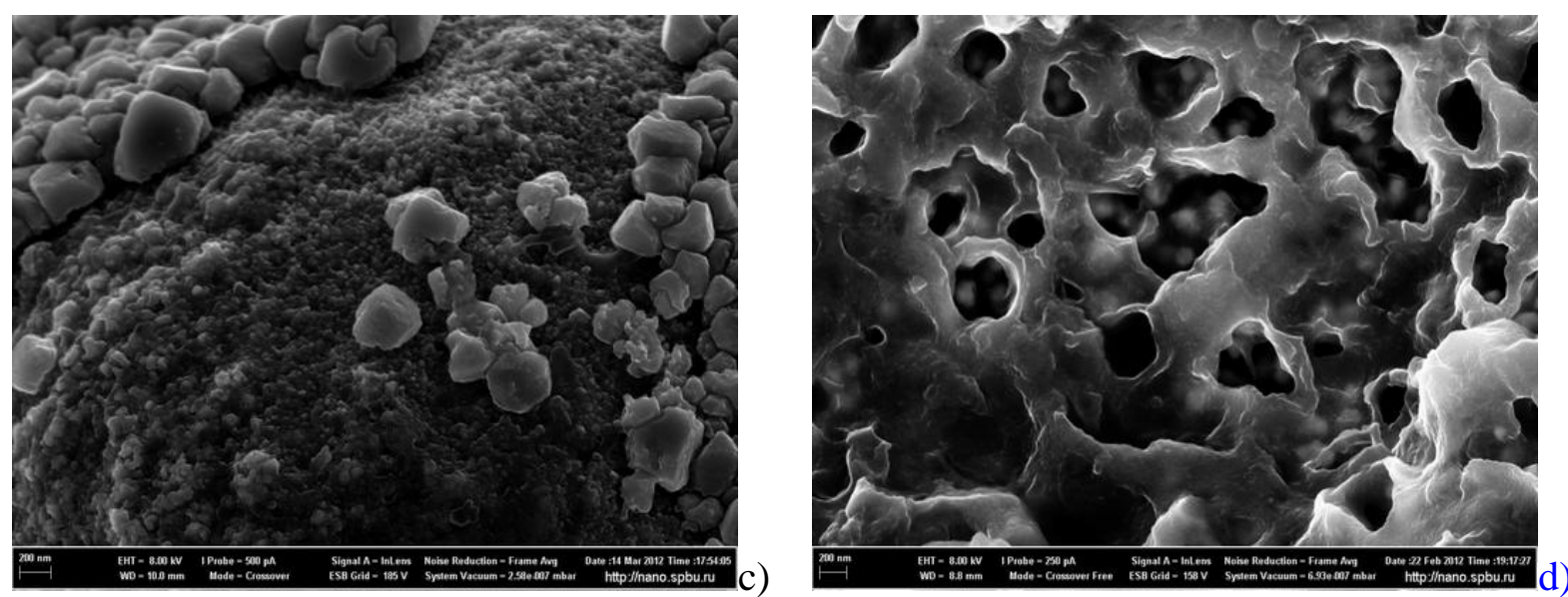

Figure 5. Microstructure of the deposit produced by LCLD. Reductants: a)ethanol; b) ethylene glycol; c)glycerol; d) xylitol.
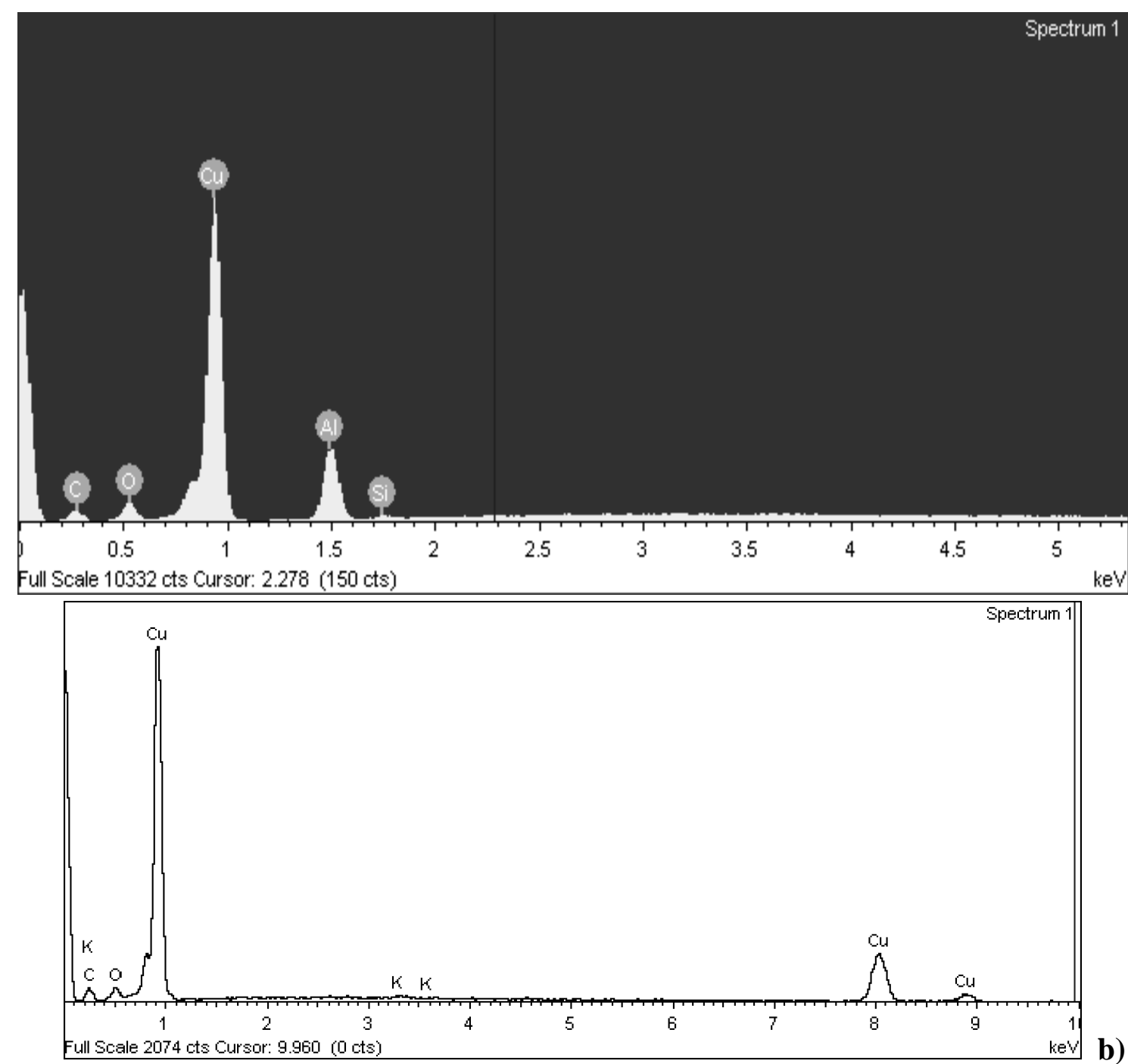

b)

Figure 6. EDX spectrum of a copper deposit produced by laser deposition of copper on the surface $f$ the glass ceramics. Reductant: a) formaldehyde; b) polyol-xylitol; the spectrum is typical of all polyols. 


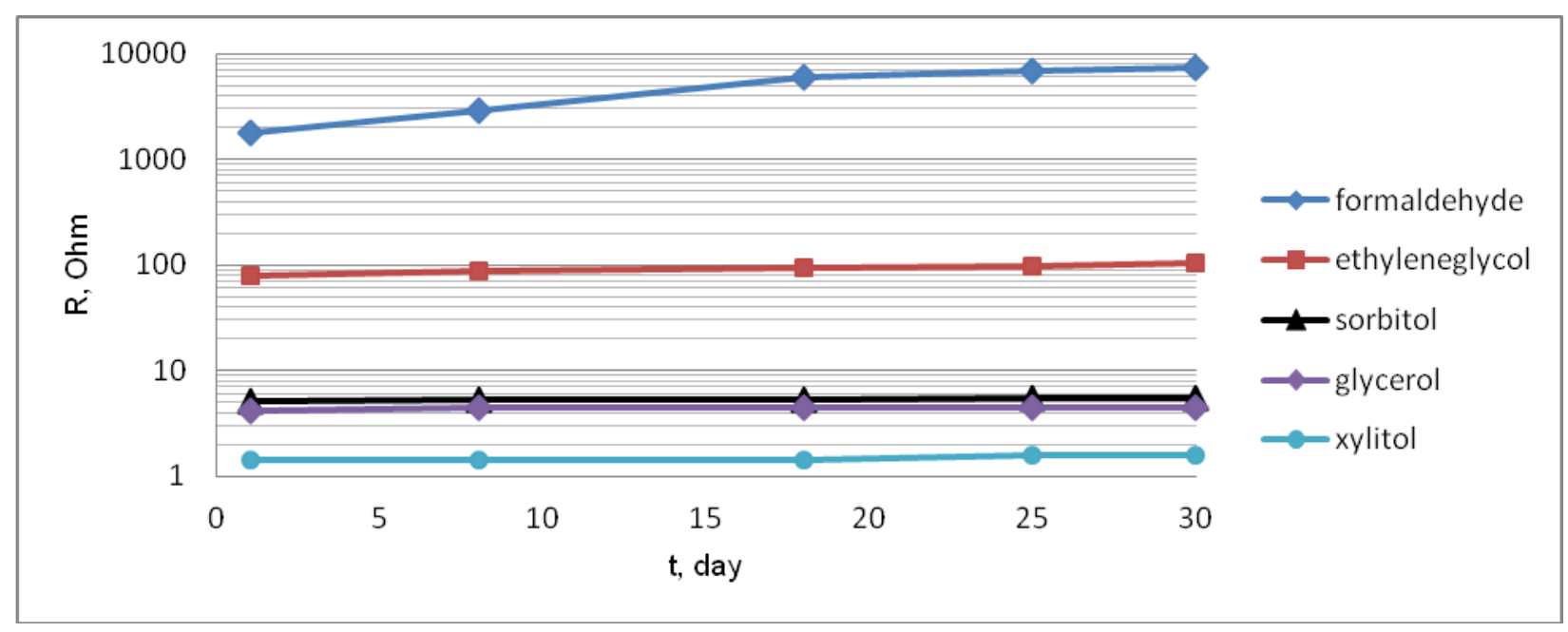

Figure 7. Dependence of the active component of electrical resistance on time using different reducing agents.

Table 1. The results of laser deposition of copper on the surface of a glass ceramics using polyols and formaldehyde as reducing agents.

\begin{tabular}{|c|c|c|c|c|c|c|}
\hline Reductant & $\begin{array}{l}\text { Formaldehyd } \\
\mathrm{e}\end{array}$ & Ethanol & $\begin{array}{l}\text { Ethylene } \\
\text { glycol }\end{array}$ & Glycerol & Xylitol & Sorbitol \\
\hline $\begin{array}{l}\text { Amount of } \mathrm{OH} \\
\text { groups }\end{array}$ & 0 & 1 & 2 & 3 & 5 & 6 \\
\hline $\begin{array}{l}\text { Conductivity of the } \\
\text { copper structure, } \\
\text { Ohm }\end{array}$ & 1900 & None & 80,0 & 4,3 & 1,5 & 5,2 \\
\hline $\begin{array}{l}\text { Copper structure } \\
\text { width }, \mu \mathrm{m}\end{array}$ & $90-120$ & $120-130$ & 130 & 170 & $150-220$ & 150 \\
\hline $\begin{array}{l}\text { Initiation } \\
\text { threshold/optimal } \\
\text { power, mW }\end{array}$ & $300 / 700$ & $300 / 900$ & $400 / 700$ & $400 / 1000$ & $400 / 1000$ & $400 / 1000$ \\
\hline $\begin{array}{l}\text { Average particles } \\
\text { size of deposit }\end{array}$ & $2-5 \mathrm{mkm}$ & $1 \mathrm{mkm}$ & $400 \mathrm{~nm}$ & $100 \mathrm{~nm}$ & $10 \mathrm{~nm}$ & $100-400 \mathrm{~nm}$ \\
\hline Topology & $\begin{array}{l}\text { Poor quality, } \\
\text { tail area (Fig } \\
6 \mathrm{e})\end{array}$ & $\begin{array}{l}\text { Quality, track } \\
\text { width } \\
\text { dispersion } \\
\text { (Fig 6a) }\end{array}$ & $\begin{array}{l}\text { Quality (Fig } \\
6 b)\end{array}$ & $\begin{array}{l}\text { Quality (Fig } \\
6 \mathrm{c} \text { ) }\end{array}$ & $\begin{array}{l}\text { Quality (Fig } \\
\text { 6d) }\end{array}$ & Quality [9] \\
\hline $\begin{array}{l}\text { Potential of the } \\
\text { half-reaction and } \\
\text { oxidation of polyol } \\
\text { at } 289 \mathrm{~K}, \mathrm{~V}^{*}\end{array}$ & -0.5 & +0.7 & +0.5 & +0.45 & +0.35 & +0.3 \\
\hline
\end{tabular}

* the values of the potential are taken as voltammetry data on anode oxidation of the organic component at the copper electrode [13-15].

\section{DISCUSSION}

The result of copper deposition from solutions with polyols, taking into account the potentials in Table 1, contradicts the theory of thermal activation of coppering with a laser beam $[2,7]$. 
In the case of formaldehyde (see [12]) the copper deposit is formed by large cubic crystals (up to $1 \mu \mathrm{m}$, Fig. 1) that form porous structures. Such deposit structure, apparently, has a small value of the effective cross-section of the conductor.

This results in that deposited copper tracks have high electrical resistance (1900 Ohms per linear centimeter). High porosity also contributes tote development of adsorption, oxidation, etc., that leads to instability of electric resistance under storage (Fig. 7).

Unlike formaldehyde, the use of polyatomic alcohols as reducing agents in the laser-induced deposition of copper from solution results in precipitation of dense deposits formed by fine nano-sized particles (Fig. 5b, c, d), which ensures a low electrical resistance value (1.5 Ohms per linear centimeter). This, in turn, significantly reduces the contribution of adsorption and surface defects in the overall conductivity of the deposit and makes it resistant to external influences after the deposition, which is reflected in the high stability of parameters of electrical conductivity in time (Fig. 7). The theory of von Gutfeld [7] and Kordas conclusions [2] of the thermal nature of laser-induced plating gives no explanation of these effects or brings them to the influence of the thermal factor. Meanwhile, simple calculations show that the thermal factor does not fully explain the result.

In fact, the half-reaction of copper reduction can be generally expressed as

$$
\mathrm{CuL}_{k}(\mathrm{OH})_{m}{ }^{2-m-k n} \rightarrow \mathrm{Cu}^{0}+\mathrm{k} L^{n-}+\mathrm{mOH} H^{-}(1)
$$

where the copper complexes with EDTA and tartrate is presented as $\mathrm{Cu}(e d t a)^{2-}$ (stability constant $\left.\beta=7^{*} 10^{17}[16]\right)$ and $\mathrm{Cu}(\operatorname{tar})_{2}(\mathrm{OH})_{2}{ }^{4-}$ (stability constant $\beta^{\prime}=2.6^{*} 10^{20}$ [17]). Reducing potentials of the complexes can be determined using the Nernst equation

$$
E^{(1)}=E_{C u^{2+} / C u^{0}}^{0}+\frac{2.3 R T}{2 F} \lg \left(\frac{\mathrm{C}_{C u L_{k}(\mathrm{OH})_{m}{ }^{2-m-k n}}}{\beta C_{L^{n-}}^{k} C_{O H^{-}}^{m}}\right)
$$

Since laser radiation can heat the solution up to the boiling temperature (from $298 \mathrm{~K}$ to $373 \mathrm{~K}$, $\Delta \mathrm{T}=75 \mathrm{~K})$, let's take into account the corresponding change in potential

$$
\Delta E_{\Delta T}^{(1)}=\int_{298}^{373} \frac{\left(S_{\mathrm{Cu}_{s}^{0}}-S_{\mathrm{Cu}_{a q}^{2+}}\right)}{2 F}-\frac{2,3 R}{2 F} \lg \left(\frac{\mathrm{C}_{\mathrm{CuL}_{k}(\mathrm{OH})_{m}{ }^{2-m-k n}}}{\beta C_{L^{n-}}^{k} C_{O H^{-}}^{m}}\right)
$$

Values of equilibrium potentials and their temperature shifts for the concentrations in use are presented in Table 2. The calculation of the results in table 2 was performed using data of standard reducing potential of copper: $\mathrm{Cu}^{2+}=\mathrm{Cu}+2 \mathrm{e}^{-} \mathrm{E}=-0,337 \mathrm{~V}$ [24], values of copper complexes constants $[16,17]$. Potentials in first column were calculated using equation (2). Second column were calculated using (3). Third column values are difference between values in columns 2 and 1. 
Table 2. Reduction potentials of copper (calculated) for copper complexes with EDTA and tartrate in concentrations used in LCLD.

\begin{tabular}{|llll|}
\hline Half-reaction & $\mathrm{E}_{298}(\mathrm{~B})$ & $\mathrm{E}_{373}(\mathrm{~B})$ & $\Delta \mathrm{E}_{\Delta \mathrm{T}}(\mathrm{B})$ \\
\hline $\mathrm{Cu}(\text { edta })^{2-} \rightarrow \mathrm{Cu}^{0}+\mathrm{edta}^{4-}$ & -0.159 & -0.233 & -0.074 \\
\hline $\mathrm{Cu}(\mathrm{tar})_{2}(\mathrm{OH})_{2}{ }^{4-} \rightarrow \mathrm{Cu}^{0}+2 \mathrm{tar}^{2-}+2 \mathrm{OH}^{-}$ & $-0,148$ & $-0,219$ & $-0,071$ \\
\hline
\end{tabular}

Table 2 shows that the reduction potential of copper(II) in solution in complexes with tartrate or EDTA not even grows, but can decrease when heated. Thus, the thermal model of LCLD [2, 18], in which the driving force of laser deposition is the heating of the solution with a laser beam, can be true only for strong reducing agents, as copper (II) doesn't become a stronger oxidizing agent when heating a solution containing the copper complex. Consider reduction potentials of reducing agents used in the work and their possible change under heating.

By similar reasoning for oxidation reactions of organic chemicals:

$$
v_{\mathrm{R}} \mathrm{Red}+v_{1} O \mathrm{H}^{-}-\mathrm{n} \bar{e} \rightarrow v_{\mathrm{O}} \mathrm{Ox}+v_{2} \mathrm{H}_{2} \mathrm{O}
$$

we get:

$\Delta E_{\Delta T} \cong \frac{2,3 R \Delta T}{n F}\left(\frac{v_{O}}{v_{R}} \lg \left(\frac{a_{\text {Red }}}{a_{0 \mathrm{x}}}\right)-v_{1} p O H\right) \cong \frac{2,3 R \Delta T}{F}\left(\frac{1}{n} \lg \left(\frac{a_{0 \mathrm{x}}}{a_{\text {Red }}}\right)-14+p H\right)$

We assume that in most reactions $v_{0}=v_{R}, v_{1}=n$ and initial concentration of the oxidized form is non-zero, and limit the latest by the assessment $\frac{a_{0 \mathrm{x}}}{a_{\text {Red }}} \geq 10^{-15}$. For $\mathrm{pH}=12.5$ we get: $\Delta E_{75} \cong 0,015\left(\frac{15}{n}-1.5\right)$; this expression will yield: $\Delta E_{75}=+0,09$ when $\mathrm{n}=2, \Delta E_{75}=0,034$ for $\mathrm{n}=$ 4 , and $\Delta E_{75} \leq 0$ for all $\mathrm{n}>6$. Given that mainly alcohols undergo oxidation to aldehydes $(\mathrm{n}=2)$ or acids $(n=4)$, we obtain the total temperature shift of the potential equal to from +0.02 to -0.04 depending on the actual ratio of oxidation products of alcohols.

Obviously, such a shift in the area of heating with a laser beam does not lead to a localized reaction proceeding exclusively in the area of radiation. The limiting minimum values of electrode potentials, which invokes notable anode currents, or the initial oxidation potentials of the used reducing agents in alkaline medium at a copper electrode are given in Table 1. Following the thermal model of LCLD [2, 18] laser copper plating is impossible for reducing agents with initial potentials of 0.15 or more.

Based on theory and experimental research one can suggest the photoemission of electrons from the surface of deposited copper into the solution at high densities of the used laser power (about $10^{5} \mathrm{~W} / \mathrm{cm}^{2}$ ). Because the used laser has the energy of radiation quanta equal to $2.33 \mathrm{eV}$ (wavelength $532 \mathrm{~nm}$ ) and the energy required for photoemission from copper into the solution at zero charge potential at the surface is $3.05 \pm 0.05 \mathrm{EV}$ [19], the single-photon processes are impossible. However, at high densities of laser radiation power multiphoton transformations become possible. In [19-21] the 
current produced by photogeneration of electrons, or the photoemission current, is given by the equation:

$$
j_{n}=L^{n} \chi(v)\left[n h v-h v_{0}-e \varphi\right]^{5 / 2}
$$

Where $L$ is light intensity, $\chi(v)$ is the function depending on properties of the metal and conditions of light absorption in the metal, $h$ is the Planck constant, $v$ is the falling light frequency, $v_{0}$ is the frequency corresponding to the to the right edge of the photoeffect, $e$ is the electron charge, $\varphi$ is the potential of the electrode relative to the zero charge point. Also, the density of the two-photon emission current is described by the experimental relation

$$
j_{2}=\eta_{2} L^{2}
$$

where $\eta_{2}$ is the probability of the two-quantum photoeffect, $L$ is light intensity. According to the experimental data in [20], for copper $\eta_{2}=1.3-7.3 \cdot 10^{-14} \mathrm{~A} \cdot \mathrm{cm}^{2} / W^{2}$. In the case of LCLD, the laser beam is focused into a spot about $10 \mu \mathrm{m}$ in diameter, therefore, within the range of used powers from $0.3 \mathrm{~W}$ to $1 \mathrm{~W}$ the photoemission current density on the radiated region will change from 3 $\mathrm{mA} / \mathrm{cm}^{2}$ to $30 \mathrm{~mA} / \mathrm{cm}^{2}$.

The photocurrent appearing under radiation must inevitably cause the change of the electrode potential according to the equation

$$
\Delta E_{p h}=\exp \left(\frac{-t}{R C}\right) \int_{0}^{t} \frac{I_{p h}\left(t^{\prime}\right) \exp \left(\frac{t^{\prime}}{R C}\right)}{C} d t
$$

where $t$ is the time, $R$ is the resistance of the electrochemical circuit, $C$ is the capacitance of the double electrical layer. However, the last two parameters are not measured for the studied solutions, so we will do a simplified calculation that takes into account only the jump of the external potential of the phase:

$$
\Delta E_{p h} \approx \Delta \varphi^{\mathrm{BH}}=\int_{0}^{t} \frac{I_{p h} d t}{4 \pi \varepsilon \varepsilon_{0} r}
$$

where $I_{p h}=j_{2} \Delta S$ is the photoemission current, $\Delta S$ is the area, $r$ is the radius of the deposited metal phase (electrode). Thus, if we take the photoemission current $j_{2}=3 * 10^{-2} \mathrm{~A} / \mathrm{cm}^{2}$ (power $1 \mathrm{~W}$ ), then for the $10 \mu \mathrm{m}$ electrode we can get $\Delta \varphi^{\mathrm{BH}} \approx 1 \mathrm{~V}$ for $t=10^{-2}$ seconds. Top jump of the external potential is limited-by the photoemission cut-off potential:

$$
\varphi=\frac{n h v-h v_{0}}{e}
$$

Moving from the zero charge potential of copper surface to the scale of the standard hydrogen electrode $\left(\varphi_{0}=-0.7 \mathrm{~V}\right)[22]$, we can approximate the limit of the external potential of copper nuclei: 


$$
\varphi=\frac{n h v-h v_{0}}{e}-\varphi_{0} \cong+0.91 \mathrm{~B}
$$

Thus $\Delta E_{p h}^{\text {lim }}=+0.91 \mathrm{~V}$, this value of the electrode potential of the copper surface makes the oxidation of polyols on the copper electrode kinetically allowed (proceeding with a non-zero rate).

On the basis of literature data (Table 1) on the values of the initial potentials of oxidation reactions for the used reducing agents and the calculated value of the potential shift on the copper surface by laser radiation, we evaluate the potential difference required for the reaction on the surface of copper with the finite rate.

Since the values in Table 1 are not equilibrium but initial potentials, $E_{\text {red }}=E_{\text {ini }}-\eta$, [23] where $\eta$ is the anodic overvoltage of the organic reagent oxidation.

Thus, knowing the initial oxidation potentials of alcohols and the reduction potential of copper complexes $E_{O X}$ (table 2), you can calculate the emf of the reduction of copper on the surface of metallic copper $\Delta E_{r}$, less the overvoltage provided the maximum possible photopotential:

$$
\Delta E_{r}-\eta=E_{O x}-\mathrm{E}_{i n i}+\Delta E_{p h}^{l i m}
$$

If this value is $>0$, then the reaction is allowed both thermodynamically (the equilibrium potential difference) and kinetically (proceeds with noticeable rate). The results of the calculations are given in Fig. 8.

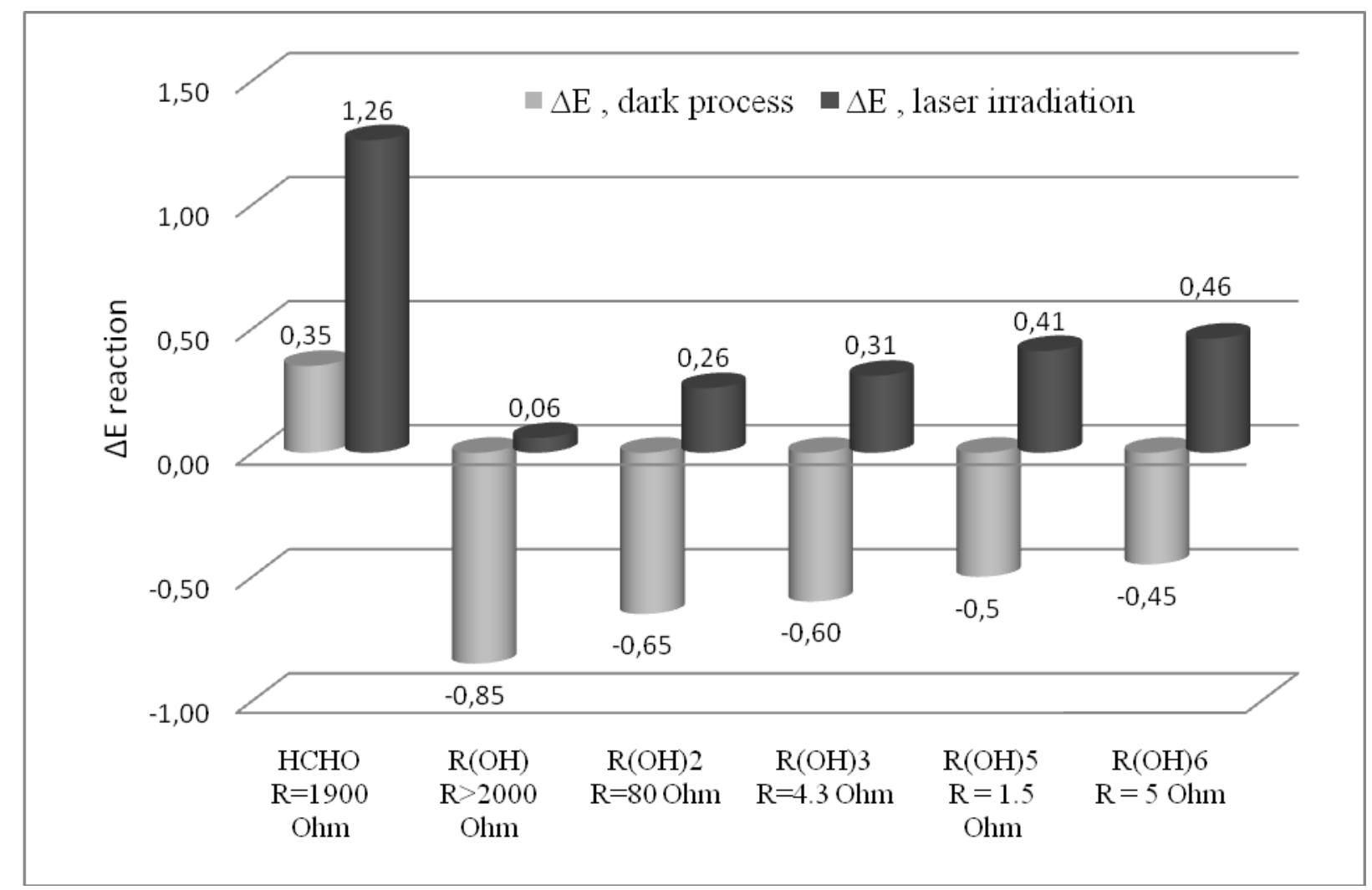

Figure 8. Chart of the values $\Delta \mathrm{E}_{\text {red }}-\eta$ at the copper surface without lighting and under the influence of laser radiation. 
As we can see from Figure 8, when using formaldehyde the reaction can proceed both under irradiation on the surface of metal nuclei formed on the dielectric (right column, $+1.26 \mathrm{~V}$ ), and in the dark in the bulk of solution (left column, $+0.35 \mathrm{~V}$ ). For this reason, we cannot make a localized compact copper deposition as nucleation occurs not only on the surface, but also in the bulk of the solution, and copper precipitates as a loose deposit (Fig. 4e), which in time (Fig. 7) increases the electrical resistance almost by an order of magnitude.

Using reducing agents with high overvoltage, the reaction proceeding without laser exposure is impossible from the point of view of the kinetics. According to the hypothesis of the photoeffect, the potential shift will lead to a local increase in the difference of potentials only at the radiated field on the surface of the metal, thus, to the local deposition of the metal on the formed nuclei, and nucleation in the solution will not proceed. If $\Delta E_{r}-\eta \leq 0$, then due to kinetic limitations the reaction will not proceed with a noticeable rate; the increase of this value according to the Butler-Folmer equation [7] will increase the deposition reaction rate and the thickness and conductivity of the tracks. This correlates with the experimental results: among all reducing agents the use of ethanol $\left(\Delta E_{r}-\eta=\right.$ $+0.06 \mathrm{~V}$, Fig. 8) leads to the formation of conductive copper structures. According to electron microscopy (Fig. 4a) copper is deposited as a very thin layer. The best results during the LCLD show glycerol, xylitol, and sorbitol $\left(\Delta E_{r}-\eta=+0.31,+0.41\right.$, and $+0.46 \mathrm{~V}$, respectively, Fig. 8$)$. For these alcohols, wide tracks are formed with good conductivity while there is no nucleation outside the radiated area because $\Delta E_{r}-\eta \leq 0$. Propylene glycol has a value of $\Delta E_{r}-\eta$ average between ethanol and polyatomic alcohols. It leads to the formation of the tracks intermediate in properties between those, which is also consistent with the hypothesis of the photoeffect. However, in the case of LCLD solutions the photoemission is not yet measured experimentally. This can be done in further work using the methods developed in [22].

\section{CONCLUSIONS}

The paper shows the possibility of managing topology and conductivity of copper structures obtained by laser deposition of copper from solution by adding to the solution organic reducing agents with different values of anodic overvoltage. For this purpose we took several polyols. It is shown that the increase of oxidation overvoltage leads to the improved topology and conductivity of deposited copper structures. Using calculations we proved that the proceeding of copper reduction by poliols with high oxidation overvoltage cannot be explained by the increase in reaction rate by heating the solution by laser. We proposed and justified the hypothesis of a two-photon photoelectric effect from the surface of deposited copper during laser deposition. Theoretical value of the locking potential is in agreement with the experimental results on the deposition of dense continuous copper structures with low electrical resistance stable in time. Thus, by attracting voltammetry measurements for polyols and forwarding the hypothesis of photoemission of electrons from the surface of copper we interpreted the mechanism of copper deposition on the surface of a dielectric under suppression of copper nucleation in the volume of solution in the course of LCLD. 


\section{ACKNOWLEDGEMENTS}

The authors gratefully acknowledge the assistance of the Interdisciplinary Resource Center for Nanotechnology and Center for optical and laser materials research of Saint-Petersburg State University. This work is supported by the Federal Targeted Program "Scientific and ScientificPedagogical Personnel of the Innovative Russia in 2009-2013" Contracts No. 8664, 14.132.21.1457.

\section{References}

1. V. A. Kochemirovsky, L. G. Menchikov, S. V Safonov, M. D. Bal'makov, I. I. Tumkin and Y. S. Tver'yanovich. Russ.Chem.Rev., 80 (2011) 869

2. P. M. K.Kordas, J.Bekesi, R.Vajtai, L.Nanai, S.Leppavuouri, A.Uusimaki, K.Bali, Thomas F.George, G.Galbacs and F.Ignacz, Appl. Surf. Sci., 172 (2011) 178

3. K.Kordas, Laser-assisted chemical liquid-phase deposition of metals for micro- and optoelectronics, $\mathrm{PhD}$ thesis, University of Oulu (2002)

4. V. A. Kochemirovsky, S. V. Safonov, I. I. Tumkin, Y. S. Tver'yanovich, I. A. Balova and L. G. Menchikov, Russ. Chem. B+, 60 (2012) 1564

5. R. J. von Gutfeld, E. E. Tynan, R. L. Melcher and S. E. Blum, Appl. Phys. Lett., 35 (1979) 651

6. R.E.Acosta, von Gutfeld, R. J., L.T.Romankiw, Thin Solid Films, 95 (1982) 131

7. R. von Gutfeld and K. Sheppard, IBM J. Res. Dev., 42 (1998) 639

8. A. Manshina, A. Povolotskiy, T. Ivanova, A. Kurochkin, Y. Tver'yanovich, D. Kim, M. Kim and S. C. Kwon, Laser. Phys. Lett., 4 (2007) 242

9. A. A. Man'shina, A. V. Povolotskiy, T. Y. Ivanova, A. V. Kurochkin, Y. S. Tver'yanovich, D. Kim, M. Kim and S. Kwon, Glass. Phys. Chem+, 33 (2007) 209

10. V.A. Kochemirovsky, E.M. Khairullina, S.V. Safonov, L.S. Logunov, I.I. Tumkin and L.G. Menchikov, Appl. Surf. Sci., 280 (2013) 494

11. V. A. Kochemirovsky, L. G. Menchikov, S. V. Safonov, M. D. Bal'makov, I. I . Tumkin and Yu. S. Tver'yanovich, Russ.Chem.Rev., 80 (2011) 869

12. V. A. Kochemirovsky, L. S. Logunov, S. V. Safonov, I. I. Tumkin, Y. S. Tver'yanovich and L. G. Menchikov, Appl. Surf. Sci., 259 (2012) 55

13. R. Ramanauskas, I. Jurgaitienst and A. Vaskelis, Electrochim. Acta, 42 (1991) 191

14. T.Paixao, D. Corbo and M. Bertotti, Anal. Chim. Acta, 472 (2002) 123

15. M.Z. Luo and R. P. Baldwin, J. Electroanal. Chem., 387 (1995) 87

16. V.M. Dubin, Y. Shacham-Diamand, B. Zhao, P.K. Vasudev and C.H.Ting, J. Electrochem. Soc. 144 (1997) 898

17. E. Norkus, V. Kepenienè, and I. Stalnioniene, Chemija, 23 (2012) 155

18. A. A. Manshina, A. V. Povolotskiy, A. V. Povolotskaya, T. Y. Ivanova, I. O. Koshevoy, S. P. Tunik, M. Suvanto, and T. A. Pakkanen, Surf. Coat. Tech., 206 (2012) 3454

19. A. M. Brodsky and Y. V Pleskov, Prog. Surf. Sci., 1 (1972) 1

20. Z.A.Rotenberg, A.M.Brodsky, Yu.Ya.Gurevich, Yu.V.Pleskov. Contemorary photoelectrochemistry.Photoemission phenomena, Nauka, Moscow (1979) (in Russian)

21. V. A. Benderskii, S. D. Babenko, Y. M. Zolotovitskii, a. G. Krivenko, and T. S. Rudenko, J. Electroanal. Chem., 56 (1974) 325

22. S.V.Ganja. Kinetics of anodic growth and properties of oxide films on poly-and monocrystalline copper and $\mathrm{Cu}$-Au alloys, $\mathrm{PhD}$ thesis, Voronezh State University, Russia (2011) (in Russian)

23. A.Frumkin, V.Bagotsky, Z.Iofa, B.Kabanov. Kinetics of electrode processes, Moscow, Moscow State Univestity, 1952 (in Russian)

24. C.D.Hogman. Handbook of Chemistry and Physics. Chemical Rubber Publishing Co, Clevelend (1955)

(C) 2014 by ESG (www.electrochemsci.org) 